\title{
MiRNAs in cancer therapy: focusing on their bi-directional roles
}

\author{
Wei He${ }^{1}$, Jinzhi $\mathrm{Xu}^{1}$, Zhen Huang ${ }^{1}$, Junfeng Zhang ${ }^{1,2^{*}}$ and Lei Dong ${ }^{1^{*}}$ (D)
}

\begin{abstract}
MicroRNA (miRNA) dysregulation is causal in most, if not all, cancers. They silence the gene's expression by modulating messenger RNA (mRNA) through employing translational repression or degradation. MiRNA has the ability to target various genes, which involve various significant signaling pathway in cancer cells, to control cancer development and progression. As a result, manipulating miRNA expression levels for cancer therapy seems an attractive and novel therapeutic approach. However, certain miRNAs, which possess the bi-directional roles, could promote cancer cells growth, but also enhance T-cell immunity. Therefore, miRNA-based therapy could also kill T cells and other lymphocytes, ultimately resulting in promoting cancer growth, which makes miRNA-based cancer therapy process with caution. In this view, we will focus on these miRNAs with the bi-directional roles, and discuss their potential effects to cancer therapy. Ultimately, identified and dissected the miRNAs crossing both T-cell-mediated anti-tumor immunity and tumor cell growth will prove vital for the design of more effective and safer strategies for cancer therapy.
\end{abstract}

Keywords: microRNA, T-cell immunity, Cancer therapy, Bi-directional roles

\section{Introduction}

MicroRNAs (miRNAs, miRs) are short (approximately 22 nucleotides), non-coding regulatory RNAs and post-transcriptionally regulate gene's expression by binding to the 3 '-untranslated region (UTR) of complementary target mRNA, causing either mRNA translation inhibition or mRNA instability [1, 2]. As crucial modulators, miRNAs participate in various biological processes such as development, differentiation, proliferation and survival, and distorted miRNAs expression and regulation has been implicated in many diverse pathologies especially in cancer $[1,3]$. The vast majority of miRNAs are deregulated in most, if not all, cancers, for example, lung cancer, breast cancer and colorectal carcinoma and so on [4-7]. Based on their functional activities, many of these miRNAs are divided in two groups: oncogenic miRNAs (oncomiRs) or tumor-supp ressive miRNAs [8]. Generally, oncomiRs are overexpressed in neoplastic or cancerous lesions, leading to down-regulating their target mRNA with an anti-cancer role such as the miR-17-92 [9]. Tumor-suppressor miRNAs, by contrast, are under-expressed in cancers; an example of this is the

\footnotetext{
* Correspondence: jfzhang@nju.edu.cn; leidong@nju.edu.cn

${ }^{1}$ State Key Laboratory of Pharmaceutical Biotechnology, NJU Advanced Institute for Life Sciences (NAILS), School of Life Sciences Nanjing University, 163 Xianlin Avenue, Nanjing 210093, China

Full list of author information is available at the end of the article
}

miR-34 family in colorectal cancer, targeting e.g. FGFR1, INHBB and AXL [10]. When oncomiRs or tumor-suppressor miRNAs are inhibited or over-expressed, respectively, cancer cell phenotype (proliferation, metastasis, drug resistance and /or survival) may be markedly reduced. Mounting evidences have revealed that suppression of oncomiRs could inhibit cancer development and progression [11]. Thus, miRNAs have become one of the most attractive and promising targets for therapeutic intervention in cancer today.

However, miRs also play a significant role in innate and adaptive immune responses. Our immune system has evolved to kill altered-self cells with high specificity throughout the whole body, and T-cell-mediated immune responses controls cancer immunosurveillance and cancer elimination [12]. Several studies have demonstrated that various levels of $\mathrm{T}$-cell immunity are regulated by specific miRNAs $[13,14]$. These miRNAs participate in generic cell biological processes in T-cell's response to different signals, such as proliferation, differentiation and function. Interestingly, recent studies reveal that both T-cell activation and cancer development may share some miRNAs $[15,16]$. Hence certain miRNAs have been shown to be oncogenic in most cancers, but also display the function of tumor elimination by regulating T-cell-mediated anti-tumor 
immune response $[17,18]$. As a result, targeting miRNA strategy deployed to inhibit cancer cell growth often eliminates $\mathrm{T}$ cells and other lymphocytes. Reversely, the approaches aimed to activate $\mathrm{T}$ cells by delivering miRNAs inhibitors or mimics may ultimately turn out to promote cancer cell proliferation in practice. The fact that the bi-directional roles of miRNAs is not a surprise due to the large number of genes modulated by a particular miRNA $[19,20]$. Therefore, focusing only tumor cell growth and ignoring their effects on T-cell proliferation and function when miRNAs as cancer therapeutics may represent an oversimplification that must be scrutinized in all cancer related miRNAs therapy studies with care. To date, this issue has been ignored, and few studies have directly tested its potential causes.

Cancer progression is not solely a function of the cancer cells themselves, but also of the cellular components and physical factors within the tumor microenvironment (TEM), leading to evading T-cell mediated immune surveillance and elimination [8]. In addition, miRNAs may have significantly influences on T-cell proliferation and function. Hence, it is necessary to consider the influence of miRNAs to both $\mathrm{T}$ cells and cancer cells themselves when testing miRNAs from a therapeutic standpoint. This view should take into account the bi-directional roles of miRNAs in both tumor cells and T cells in cancer therapy, not just the effects of the miRNAs that are specific to the cancer cells themselves. Here, we present several examples of when a miRNA exerts an oncogenic or tumor suppressive effect on the cancer cells themselves but an anti-cancer or pro-cancer effect by regulating T-cell-mediated anti-tumor immune response, or vice versa (summarized in Fig. 1).

\section{Bi-directional roles of miRNAs in cancer cells and T cells MiRNA-21}

As the most prominent example of a miRNA that could as either an oncomiR in cancer cell themselves or a tumor suppressor via regulating $\mathrm{T}$ cells proliferation and

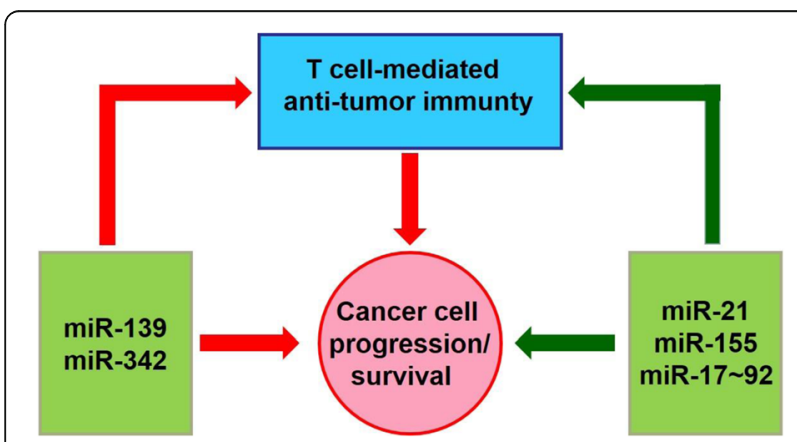

Fig. 1 Examples of miRNAs that have the bi-directional roles in cancer therapy. miRNAs inhibition or overexpression may promote cancer cells growth, but also enhance T-cell immunity. Green arrows, positive regulation; red arrows, negative regulation activation, we consider miR-21. As one of the first identified oncomiRs, miR-21 has been shown to be the most generally over-expressed miRNA in the vast majority of solid and hematological malignancies [21]. Extensive studies have implicated the integral role of miR-21 in tumor pathogenesis and during all other stages of carcinogenesis, as follows: i) down-regulation of miR-21 in glioblastoma cells could induce caspases activation and promote apoptosis, which shows that miR-21 can serve as an anti-apoptotic factor [22]. ii) In response to mouse skin carcinogenesis protocol, absence of miR-21 in mice showed a marked decrease in papilloma formation, and overexpression of miR-21 in vivo leads to a pre-B malignant lymphoid-like phenotype and promotes Kras-mediated lung tumorigenesis [23-25]. iii) Metastasis is a key factor of cancer-related death, knock down of miR-21 in B16 cells result in decreasing extravasation and distal metastasis, and the survival rate of the mice tail-vein injected with miR-21 $1^{-1}$ B16 cells was markedly enhanced, suggesting that miR-21 acts as an pro-metastatic factor [26]. iv): Drug resistance is a major clinical obstacle to the successful treatment of cancer. Prior studies have shown that over-expression of miR-21 leads to chemoresistance in several cancer types, such as breast and ovarian cancer [7, 27]. v): knock down of miR-21 in hepatocellular carcinoma cells could reduce tumor cell proliferation, migration, and cell cycle [28]. The oncogenic activity of miR-21 may be reconciled by taking into account the fact that each miRNA has the capacity of targeting tens to hundreds of different genes. In the case of miR-21, targets include mRNA encoding anti-apoptotic factors (BCL-2, TIMP3, FASL, BMPR2, PDCD4 and PTEN), Pro-proliferative factors (PTEN, SPR Y1/2, TGFBR2 and HNRPK), invasion and metastasis promoters (PPARA, TPM1, TIMP3 and MARCKS), and pro-angiogenesis factors (TIMP3 and RECK) [29]. Therefore, several studies have been showed that miR-21 may act as a novel therapeutic target for human cancer, and inhibiting miR-21 in cancer cells has achieved some success.

However, miR-21 also plays a major role in regulating T-cell immunity. MiR-21 expression is induced during T cell proliferation and function [30]. MiR-21 inhibits apoptosis in activated $\mathrm{T}$ cells in part via targeting tumor suppressor gene Tipe2, and also regulates $\mathrm{T}$ lymphocyte activation by increasing IL-2, Rab34 and Tri1 expression $[31,32]$. Further supporting the function of miR-21 in $\mathrm{T}$ cells activation is that miRNA-21 depletion impaired T-cell-mediated immune response to stimulations [33]. In addition, an analogous role for miR-21 was found for tumor-associated T cells. MiR-21 ${ }^{-/-}$mice could accelerated the grafted tumor growth via slowing both $\mathrm{CD} 4^{+}$ and $\mathrm{CD}^{+}$cells proliferation as well as reducing their cytokine production. Although deletion of miR-21 in cancer cells could significantly retard cancer growth [34], systematic injection of anti-miR-21 oligonucleotides 
did not show marked inhibition of the anti-cancer ability in the tumor-bearing animals, possible because miR-21 inhibition in cancer cells was compensated by the reduction of the activity of the $\mathrm{T}$ cell-mediated anti-cancer immune response by the anti-miR-21 strategy [15]. Together, these studies clearly demonstrated that the importance of considering miR-21's role in tumor-infiltrating $\mathrm{T}$ cells when designing miR-21-based therapeutics.

\section{MiRNA-155}

Another typical example of this phenomenon is provided by miR-155. Similar to miR-21, miR-155 is commonly over-expressed in a large number of solid and hematological malignancies, and has been involved in the development of leukemia, colon and prostate cancer [35-38]. Over-expression of miR-155 in B cells in mice could induce a preleukemic pre-B cell proliferation and ultimately lead to a frank B cell malignancy [39]. Some of targets (TP53INP, SOCS1, CEBPB and APC) of miR-155 control apoptosis, proliferation, cell cycle progression, invasion, migration and stemness [40]. In addition, miR-155 overexpression is also involved in genome instability and drug resistance, for example, miR-155 overexpression could increase mutation and enhance genomic instability by targeting MLH1 and MSH2/6 via affecting multiple DNA repair pathways [41], as well as down-regulation of miR-155 successfully resensitizes tumors to multiple chemotherapeutic agents in an orthotropic lung cancer model [42]. Meanwhile, silence of miR-155 was also successfully used in miR-155 overexpressed lymphomas treatment [43].

However, there is an interesting overlap that miR-155 is considered as an oncomiR, but also plays important roles in anti-cancer immune response [44]. MiR-155 is associated with Th1/Th2 differentiation. Up-regulation of miR-155 in naive $\mathrm{CD}^{+} \mathrm{T}$ cells leads to polarized differentiation preferentially into Th1 cells by targeting the IFN- $\gamma$ receptor alpha chain (IFNGR1). Reversely, CD4 ${ }^{+} \mathrm{T}$ cells lacking miR-155 were more prone to polarize towards Th2 cells, as well as decrease IFN- $\gamma$ and IL-2 secretion upon antigenic stimuli [45-47]. In addition, miR-155 also targets CTLA-4 (cytotoxic T-lymphocyte antigen-4), a negative regulator of T-cell activation, suggesting that a second, independent pathway via miR-155 enhancing T cell activation [48]. Also, absence of miR-155 could weaken $\mathrm{T}$ cell trafficking and antiviral $\mathrm{CD}^{+} \mathrm{T}$ cell responses [49-52]. These studies implies that deletion of miR-155 in tumor-associated T cells might inhibit anti-cancer immune response and promote rather than retard tumor growth. This notion is supported by the fact that $m i R-155^{-/-} \mathrm{CD}^{+} \mathrm{T}$ cells were ineffective at inhibiting tumor growth [17]. Based on the effects on T-cell immunity and cancer cells themselves, the use of antimiR-155 as a cancer therapeutic approach should proceed with caution.

\section{$\operatorname{miR}-17-92$}

Other example of miRNAs that may have the bi-directional roles of miRNAs in cancer cells and T cells are miR-17-92. MiR-17-92 have been identified to be up-regulated in various cancers, such as breast cancer, colon cancer and gastric cancer, enhances proliferation, inhibit apoptosis, and confer pro-metastasis function in cancers, thereby promoting cancer-progression [9, 53-55]. However, several studies have demonstrated that the miR-17-92 cluster promoted polarization towards a type 1 phenotype, for example, miR-19b and miR-17 were crucial in enhancing Th1 responses and inhibiting differentiation into inducible Tregs (regulatory $\mathrm{T}$ cells) by down-regulating their target genes, such as PTEN (miR-19b), TGFßRII and CREB1 (both miR-17) [56-58]. In addition, miR-17-92 is also up-regulated in $\mathrm{CD}^{+} \mathrm{T}$ cells, could promote IFN- $\gamma$ secretion, and enhance cytotoxicity in response to stimulation. Also, miR-17-92 increases the frequency of $\mathrm{CD}^{+}$memory T-cells produce IFN- $\gamma$, as well as resists TGF- $\beta$-mediated suppression $[59,60]$. In a word, these results emphasize the great complexity of the miRNA's function in tumor therapy.

\section{Other miRNAs}

Other miRNAs such as miR-139 and miR-342, have also similar roles in both cancer cells and T cells. Both miRNAs could target several oncogenes and are classified as tumor suppressor in various cancers [61-63]. However, miR-139 and miR-342 inhibition could boost $\mathrm{T}$ cell cytotoxicity by down-regulating perforin and EOMES expression [64]. Thus, testing a miRNA's effect on both T-cell immunity and cancer cells themselves may be of the utmost importance when development a miRNA-based therapeutic agents for cancer.

\section{The effect on cancer therapy of their bi-directional roles}

As a novel therapeutic option, regulatory miRNAs to retard cancer development and progression even eliminate cancer are attracting more and more attention [65]. However, their bi-directional roles may be an obstacle for miRNA-based therapies to clinical treatment. Restoring miRNA function using a synthetic miRNA (for tumor suppressor miRNAs) or suppressing the activity of a miRNA by anti-miRNA oligonucleotides (for oncogenic miRNAs) could inhibit cancer cells proliferation, metastases and so on, but they could also affect the anti-tumor function of immune cells especially $\mathrm{T}$ cells, in tumor microenvironment. Hence delivering miRNA mimics or anti-miRNAs into cancer tissues may not exert their anti-tumor effect, possible because miRNAs suppression or over-expression in tumor cells to retard tumor growth is neutralized by the inhibition of the function of the $\mathrm{T}$ cell-medicated anti-tumor immunity by the targeting miRNAs strategy, for example, anti-miR-21 approach [15]. To overcome the 
barrier, efforts should be made to develop novel and specifically targeted systems to tumor cells to avoid the influence of miRNAs to T cell-medicated anti-tumor immunity [66].

In addition, manipulating miRNAs for $\mathrm{T}$ cells to improve the anti-tumor activity of adoptively transferred tumor-reactive $\mathrm{T}$ cells should be a more promising approach for miRNA-based cancer therapies. It has been proved to be effective that $\mathrm{T}$ cells could be isolated, treated with miRNAs mimics or anti-miRNAs oligonucleotides and then reintroduced into tumor-bearing animals [67]. MiRNAs could improve adoptive T cell immunotherapy from the following aspects: (1) boosting TCR sensitivity, some miRNAs could regulates TCR signaling by targeting key inhibitory phosphatases (DUSP10 or PTPN2) to promote $\mathrm{T}$ cell activation such as miR-21 and miR-155 [14]; (2) enhancing $\mathrm{T}$ cell fitness, overexpressing miR-17 92 in anti-EGFRvIII CAR-modified $\mathrm{T}$ cells could enhance their anti-tumor activity [68]; (3) augmenting effector functions, miR-139 and miR-342 inhibition could promote $\mathrm{T}$ cell effector functions [64].

\section{Conclusions}

Adoptive cell transfer (ACT)-based immunotherapy, especially microRNA-based redirected tumor-reactive $\mathrm{T}$ cells, has shown promise as a potentially curative means for patients with advanced cancer. Although some miRNAs (miR-21 and miR-155 and so on) have dual roles in tumor progression, they are also key regulators of $\mathrm{T}$ cell activation, proliferation and effector functions, which are all important factors involving the therapeutic outcome of ACT-based immunotherapy. Meanwhile, miRNA-based therapy offers some advantages over other gene engineering strategies and protein-target-based immune modulation, for example, miRNAs could target multiple molecules simultaneously, and manipulating a single miRNA could rebuild $\mathrm{T}$ cell behavior and bypass the need for complex transcriptional reprogram. Lastly, due to their small size, miRNA mimics and inhibitors could be easily integrated into existing multicistronic TCR and CAR platforms. Therefore, a further understanding of the role that miRNAs play in $\mathrm{T}$ cell fate and behavior is driving us closer to the prospect of safe and effective miRNA-based redirected $\mathrm{T}$ cell therapies.

In addition, the complexity of cancer development and progression make development a cancer therapeutic approach need to think about the effects to both cancer cells and tumor-associated $\mathrm{T}$ cells, especially miRNAmodulating therapies. Targeting miRNAs could simultaneously effect on many genes expression and even certain key signaling pathways, which participate in both T-cell proliferation and cancer development, such as NF- $\mathrm{kB}$ and Akt pathways. Hence, this phenomenon is really possible that miRNA-based therapy ultimately results in promoting cancer growth. Depending on the balance between modulation of miRNAs in cancer cells and the effects of the
miRNAs on T-cell-mediated anti-cancer immunity, the miRNAs may produce an overall net anti-cancer or net pro-cancer effects. Preclinical trials show lots of miRNAs with significantly potential in cancer therapy, but these data are mainly from miRNAs-modulated tumor cells using in vitro and immunocompromised xenograft models, and eliminate the effects of miRNAs to T-cell-mediated anticancer immune response. To then end, we strongly recommend the use of immunocompetent mouse models in preclinical trials of potential miRNA therapeutics to give consideration to our body immune system and cancer cells themselves. Therefore, identified and dissected the miRNAs crossing both T-cell immunity and cancer cell growth is of the utmost importance, as there is currently plenty of excitement in the administration of exogenous miRNAs mimics and miRNAs inhibitors for controlling cancer growth. Such studies may be necessary and urgent in driving miRNA-based therapeutics from preclinical trials to clinical practice.

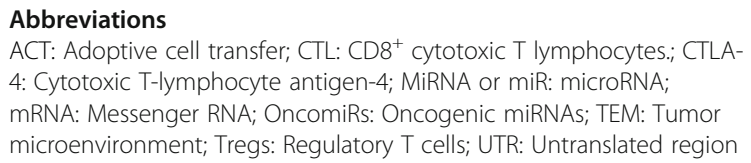

Acknowledgments

Not applicable.

\section{Funding}

This seminar was supported by the National High Technology Research and Development Program of China (2014AA020707), the National Natural Science Foundation of China $(31271013,51173076,51503232,91129712$ and 81102489), the Program for New Century Excellent Talents in University (NCET-13-0272).

Availability of data and materials Not applicable.

Authors' contributions

W. H., J. Z. and L. D. conceived this seminar. W. H., J. X. and Z. H. wrote the manuscript. All authors read and approved the final manuscript.

Ethics approval and consent to participate

Not applicable.

Consent for publication

Not applicable.

Competing interests

The authors declare that they have no competing interests.

\section{Publisher's Note}

Springer Nature remains neutral with regard to jurisdictional claims in published maps and institutional affiliations.

\section{Author details}

'State Key Laboratory of Pharmaceutical Biotechnology, NJU Advanced Institute for Life Sciences (NAILS), School of Life Sciences Nanjing University, 163 Xianlin Avenue, Nanjing 210093, China. ${ }^{2}$ Jiangsu Provincial Laboratory for Nano-Technology, Nanjing University, Nanjing, People's Republic of China. 
Received: 5 October 2017 Accepted: 2 January 2019 Published online: 14 February 2019

\section{References}

1. Romero-Cordoba SL, Salido-Guadarrama I, Rodriguez-Dorantes M, HidalgoMiranda A. Mirna biogenesis: biological impact in the development of cancer. Cancer biology \& therapy. 2014;15:1444-55.

2. Bartel DP. Micrornas: genomics, biogenesis, mechanism, and function. Cell. 2004;116:281-97.

3. Palanichamy JK, Rao DS. Mirna dysregulation in cancer: towards a mechanistic understanding. Front Genet. 2014:5:54.

4. Reddy KB. Microrna (mirna) in cancer. Cancer Cell Int. 2015;15:38.

5. Dong $Y, Y$ U J, Ng SS. Microrna dysregulation as a prognostic biomarker in colorectal cancer. Cancer Manag Res. 2014;6:405-22.

6. Inamura K. Major tumor suppressor and oncogenic non-coding rnas: clinical relevance in lung cancer. Cells. 2017;6.

7. Teoh SL, Das S. The role of micrornas in diagnosis, prognosis, metastasis and resistant cases in breast cancer. Curr Pharm Des. 2017;23:1845-59.

8. Svoronos AA, Engelman DM, Slack FJ. Oncomir or tumor suppressor? The duplicity of micrornas in cancer. Cancer Res. 2016;76:3666-70.

9. Fuziwara CS, Kimura ET. Insights into regulation of the mir-17-92 cluster of mirnas in cancer. Frontiers in medicine. 2015;2:64.

10. Jiang $L$, Hermeking $H$. Mir-34a and mir-34b/c suppress intestinal tumorigenesis. Cancer Res. 2017;77:2746-58.

11. Rupaimoole R, Slack FJ. Microrna therapeutics: towards a new era for the management of cancer and other diseases. Nat Rev Drug Discov. 2017;16: 203-22.

12. Schreiber RD, Old LJ, Smyth MJ. Cancer immunoediting: integrating immunity's roles in cancer suppression and promotion. Science. 2011;331: $1565-70$.

13. Kroesen BJ, Teteloshvili N, Smigielska-Czepiel K, Brouwer E, Boots AM, van den Berg A, Kluiver J. Immuno-mirs: critical regulators of t-cell development, function and ageing. Immunology. 2015;144:1-10.

14. Ji Y, Hocker JD, Gattinoni L. Enhancing adoptive t cell immunotherapy with microrna therapeutics. Semin Immunol. 2016;28:45-53.

15. He W, Wang C, Mu R, Liang P, Huang Z, Zhang J, Dong L. Mir-21 is required for anti-tumor immune response in mice: an implication for its bi-directional roles. Oncogene. 2017;36:4212-23.

16. Si ML, Zhu S, Wu H, Lu Z, Wu F, Mo YY. Mir-21-mediated tumor growth. Oncogene. 2007;26:2799-803.

17. Ji Y, Wrzesinski C, Yu Z, Hu J, Gautam S, Hawk NV, Telford WG, Palmer DC, Franco Z, Sukumar M, Roychoudhuri R, Clever D, Klebanoff CA, Surh CD, Waldmann TA, Restifo NP, Gattinoni L. Mir-155 augments cd8+t-cell antitumor activity in lymphoreplete hosts by enhancing responsiveness to homeostatic gammac cytokines. Proc Natl Acad Sci U S A. 2015;112:476-81.

18. Higgs $G$, Slack $F$. The multiple roles of microrna-155 in oncogenesis. Journal of clinical bioinformatics. 2013;3:17

19. Lewis BP, Burge CB, Bartel DP. Conserved seed pairing, often flanked by adenosines, indicates that thousands of human genes are microrna targets. Cell. 2005;120:15-20.

20. Rajewsky N. Microrna target predictions in animals. Nat Genet. 2006; 38(Suppl):S8-13.

21. Pfeffer SR, Yang CH, Pfeffer LM. The role of mir-21 in cancer. Drug Dev Res. 2015;76:270-7.

22. Papagiannakopoulos T, Shapiro A, Kosik KS. Microrna-21 targets a network of key tumor-suppressive pathways in glioblastoma cells. Cancer Res. 2008; 68:8164-72.

23. Ma X, Kumar M, Choudhury SN, Becker Buscaglia LE, Barker JR, Kanakamedala K, Liu MF, Li Y. Loss of the mir-21 allele elevates the expression of its target genes and reduces tumorigenesis. Proc Natl Acad Sci U S A. 2011;108:10144-9.

24. Medina PP, Nolde M, Slack FJ. Oncomir addiction in an in vivo model of microrna-21-induced pre-b-cell lymphoma. Nature. 2010:467:86-90.

25. Frezzetti D, De Menna M, Zoppoli P, Guerra C, Ferraro A, Bello AM, De Luca P, Calabrese C, Fusco A, Ceccarelli M, Zollo M, Barbacid M, Di Lauro R, De Vita G. Upregulation of mir-21 by ras in vivo and its role in tumor growth. Oncogene. 2011;30:275-86

26. Yang $\mathrm{CH}$, Yue J, Pfeffer SR, Handorf CR, Pfeffer LM. Microrna mir-21 regulates the metastatic behavior of b16 melanoma cells. J Biol Chem. 2011;286: 39172-8.
27. Xie Z, Cao L, Zhang J. Mir-21 modulates paclitaxel sensitivity and hypoxiainducible factor-1alpha expression in human ovarian cancer cells. Oncol Lett. 2013;6:795-800

28. Wu H, Ng R, Chen X, Steer CJ, Song G. Microrna-21 is a potential link between non-alcoholic fatty liver disease and hepatocellular carcinoma via modulation of the hbp1-p53-srebp1c pathway. Gut. 2016;65:1850-60.

29. Buscaglia LE, Li Y. Apoptosis and the target genes of microrna-21. Chinese journal of cancer. 2011;30:371-80.

30. Teteloshvili N, Smigielska-Czepiel K, Kroesen BJ, Brouwer E, Kluiver J, Boots AM, van den Berg A. T-cell activation induces dynamic changes in mirna expression patterns in cd4 and cd8 t-cell subsets. MicroRNA. 2015;4:117-22.

31. Wang L, He L, Zhang R, Liu X, Ren Y, Liu Z, Zhang X, Cheng W, Hua ZC. Regulation of t lymphocyte activation by microrna-21. Mol Immunol. 2014;59:163-71.

32. Ruan Q, Wang P, Wang T, Qi J, Wei M, Wang S, Fan T, Johnson D, Wan X, Shi W, Sun H, Chen YH. Microrna-21 regulates t-cell apoptosis by directly targeting the tumor suppressor gene tipe2. Cell Death Dis. 2014;5:e1095.

33. Murugaiyan G, da Cunha AP, Ajay AK, Joller N, Garo LP, Kumaradevan S, Yosef N, Vaidya VS, Weiner HL. Microrna-21 promotes th17 differentiation and mediates experimental autoimmune encephalomyelitis. J Clin Invest. 2015;125:1069-80

34. Leone E, Morelli E, Di Martino MT, Amodio N, Foresta U, Gulla A, Rossi M, Neri A, Giordano A, Munshi NC, Anderson KC, Tagliaferri P, Tassone P. Targeting mir-21 inhibits in vitro and in vivo multiple myeloma cell growth. Clinical cancer research : an official journal of the American Association for Cancer Research. 2013;19:2096-106.

35. Moridikia A, Mirzaei H, Sahebkar A, Salimian J. Micrornas: potential candidates for diagnosis and treatment of colorectal cancer. J Cell Physiol. 2017.

36. Jurkovicova D, Magyerkova M, Kulcsar L, Krivjanska M, Krivjansky V, Gibadulinova A, Oveckova I, Chovanec M. Mir-155 as a diagnostic and prognostic marker in hematological and solid malignancies. Neoplasma. 2014;61:241-51.

37. Cai ZK, Chen Q, Chen YB, Gu M, Zheng DC, Zhou J, Wang Z. Microrna-155 promotes the proliferation of prostate cancer cells by targeting annexin 7 . Mol Med Rep. 2015;11:533-8.

38. Narayan N, Morenos L, Phipson B, Willis SN, Brumatti G, Eggers S, Lalaoui N, Brown LM, Kosasih HJ, Bartolo RC, Zhou L, Catchpoole D, Saffery R, Oshlack A, Goodall GJ, Ekert PG. Functionally distinct roles for different mir-155 expression levels through contrasting effects on gene expression, in acute myeloid leukaemia. Leukemia. 2017;31:808-20.

39. Costinean S, Zanesi N, Pekarsky Y, Tili E, Volinia S, Heerema N, Croce CM. Pre-b cell proliferation and lymphoblastic leukemia/high-grade lymphoma in e(mu)-mir155 transgenic mice. Proc Natl Acad Sci U S A. 2006;103:7024-9.

40. Catela Ivkovic T, Voss G, Cornella H, Ceder Y. Micrornas as cancer therapeutics: a step closer to clinical application. Cancer Lett. 2017;407:113-22.

41. Czochor JR, Sulkowski P, Glazer PM. Mir-155 overexpression promotes genomic instability by reducing high-fidelity polymerase delta expression and activating error-prone dsb repair. Mol Cancer Res. 2016;14:363-73.

42. Van Roosbroeck K, Fanini F, Setoyama T, Ivan C, Rodriguez-Aguayo C, Vannini I, Redis RS, D'Abundo L, Zhang X, Xiao L, Nicoloso MS, Rossi S, Gonzalez-Villasana V, Rupaimoole R, Ferracin M, Morabito F, Neri A, Ruvolo PP, Ruvolo VR, Pecot CV, Amadori D, Abruzzo L, Calin S, Wang X, You MJ, Ferrajoli A, Orlowski R, Plunkett W, Davuluri RV, Berindan-Neagoe I, Negrini M, Wistuba II, Kantarjian HM, Sood AK, Lopez-Berestein G, Keating MJ, Fabbri M, Calin GA. Combining anti-mir-155 with chemotherapy for the treatment of lung cancers. Clin Cancer Res. 2017;23:2891-904.

43. Cheng CJ, Bahal R, Babar IA, Pincus Z, Barrera F, Liu C, Svoronos A, Braddock DT, Glazer PM, Engelman DM, Saltzman WM, Slack FJ. Microrna silencing for cancer therapy targeted to the tumour microenvironment. Nature. 2015;518:107-10.

44. Xiao C, Rajewsky K. Microrna control in the immune system: basic principles. Cell. 2009;136:26-36.

45. Banerjee A, Schambach F, DeJong CS, Hammond SM, Reiner SL. Micro-rna155 inhibits ifn-gamma signaling in cd4+ t cells. Eur J Immunol. 2010;40: 225-31.

46. Rodriguez A, Vigorito E, Clare S, Warren MV, Couttet P, Soond DR, van Dongen S, Grocock RJ, Das PP, Miska EA, Vetrie D, Okkenhaug K, Enright AJ, Dougan $\mathrm{G}$, Turner M, Bradley A. Requirement of bic/microrna-155 for normal immune function. Science. 2007;316:608-11.

47. Thai TH, Calado DP, Casola S, Ansel KM, Xiao C, Xue Y, Murphy A, Frendewey D, Valenzuela D, Kutok JL, Schmidt-Supprian M, Rajewsky N, Yancopoulos G, Rao A, Rajewsky K. Regulation of the germinal center response by microrna-155. Science. 2007;316:604-8. 
48. Sonkoly E, Janson P, Majuri ML, Savinko T, Fyhrquist N, Eidsmo L, Xu N, Meisgen F, Wei T, Bradley M, Stenvang J, Kauppinen S, Alenius H, Lauerma A, Homey B, Winqvist O, Stahle M, Pivarcsi A: Mir-155 is overexpressed in patients with atopic dermatitis and modulates t-cell proliferative responses by targeting cytotoxic t lymphocyte-associated antigen 4. The J Allergy Clin Immunol 2010;126:581-589 e581-520.

49. Tsai CY, Allie SR, Zhang W, Usherwood EJ. Microrna mir-155 affects antiviral effector and effector memory cd8 t cell differentiation. J Virol. 2013;87:2348-51.

50. Dudda JC, Salaun B, Ji Y, Palmer DC, Monnot GC, Merck E, Boudousquie C, Utzschneider DT, Escobar TM, Perret R, Muljo SA, Hebeisen M, Rufer N, Zehn D, Donda A, Restifo NP, Held W, Gattinoni L, Romero P. Microrna-155 is required for effector $c d 8+t$ cell responses to virus infection and cancer. Immunity. 2013;38:742-53.

51. Lind EF, Elford AR, Ohashi PS. Micro-rna 155 is required for optimal cd8 $+t$ cell responses to acute viral and intracellular bacterial challenges. J Immunol. 2013;190:1210-6.

52. Dickey $\mathrm{LL}$, Worne $\mathrm{CL}$, Glover $\mathrm{JL}$, Lane $\mathrm{TE}$, O'Connell RM. Microrna-155 enhances $t$ cell trafficking and antiviral effector function in a model of coronavirus-induced neurologic disease. J Neuroinflammation. 2016;13:240.

53. Li H, Wu Q, Li T, Liu C, Xue L, Ding J, Shi Y, Fan D. The mir-17-92 cluster as a potential biomarker for the early diagnosis of gastric cancer: evidence and literature review. Oncotarget. 2017;8:45060-71.

54. Concepcion CP, Bonetti C, Ventura A. The microrna-17-92 family of microrna clusters in development and disease. Cancer J. 2012;18:262-7.

55. Farazi TA, Horlings HM, Ten Hoeve JJ, Mihailovic A, Halfwerk H, Morozov P, Brown M, Hafner M, Reyal F, van Kouwenhove M, Kreike B, Sie D, Hovestadt $V$, Wessels LF, van de Vijver MJ, Tuschl T. Microrna sequence and expression analysis in breast tumors by deep sequencing. Cancer Res. 2011;71:4443-53.

56. Sasaki K, Kohanbash G, Hoji A, Ueda R, McDonald HA, Reinhart TA, Martinson J, Lotze MT, Marincola FM, Wang E, Fujita M, Okada H. Mir-17-92 expression in differentiated t cells - implications for cancer immunotherapy. J Transl Med. 2010;8:17.

57. Jiang S, Li C, Olive V, Lykken E, Feng F, Sevilla J, Wan Y, He L, Li QJ. Molecular dissection of the mir-17-92 cluster's critical dual roles in promoting th1 responses and preventing inducible treg differentiation. Blood. 2011;118:5487-97.

58. Skinner JP, Keown AA, Chong MM. The mir-17 approximately 92a cluster of micrornas is required for the fitness of foxp3+ regulatory $t$ cells. PLoS One. 2014:9:e88997.

59. Kosaka A, Ohkuri T, Ikeura M, Kohanbash G, Okada H. Transgene-derived overexpression of mir-17-92 in cd8+ t-cells confers enhanced cytotoxic activity. Biochem Biophys Res Commun. 2015;458:549-54

60. Wu T, Wieland A, Araki K, Davis CW, Ye L, Hale JS, Ahmed R. Temporal expression of microrna cluster mir-17-92 regulates effector and memory cd8 + t-cell differentiation. Proc Natl Acad Sci U S A. 2012;109:9965-70.

61. Wang H, Wu J, Meng X, Ying X, Zuo Y, Liu R, Pan Z, Kang T, Huang W. Microrna-342 inhibits colorectal cancer cell proliferation and invasion by directly targeting DNA methyltransferase 1. Carcinogenesis. 2011;32:1033-42.

62. Pajic M, Froio D, Daly S, Doculara L, Millar E, Graham PH, Drury A, Steinmann A, de Bock CE, Boulghourjian A, Zaratzian A, Carroll S, Toohey J, O'Toole SA, Harris AL, Buffa FM, Gee HE, Hollway GE, Molloy TJ. Mir-139-5p modulates radiotherapy resistance in breast cancer by repressing multiple gene networks of DNA repair and ros defense. Cancer Res. 2017.

63. Qin L, Deng HY, Chen SJ, Wei W, Zhang YT. Mir-139 acts as a tumor suppressor in t-cell acute lymphoblastic leukemia by targeting $c x$ chemokine receptor 4. Am J Transl Res. 2017;9:4059-70.

64. Trifari S, Pipkin ME, Bandukwala HS, Aijo T, Bassein J, Chen R, Martinez GJ, Rao A. Microrna-directed program of cytotoxic cd8+t-cell differentiation. Proc Natl Acad Sci U S A. 2013;110:18608-13.

65. Abba ML, Patil N, Leupold JH, Moniuszko M, Utikal J, Niklinski J, Allgayer H. Micrornas as novel targets and tools in cancer therapy. Cancer Lett. 2017:387:84-94.

66. Fernandez-Pineiro I, Badiola I, Sanchez A. Nanocarriers for microrna delivery in cancer medicine. Biotechnol Adv. 2017;35:350-60.

67. Lin R, Chen L, Chen G, Hu C, Jiang S, Sevilla J, Wan Y, Sampson JH, Zhu B, Li QJ. Targeting mir-23a in cd8+ cytotoxic t lymphocytes prevents tumordependent immunosuppression. J Clin Invest. 2014;124:5352-67.

68. Ohno M, Ohkuri T, Kosaka A, Tanahashi K, June CH, Natsume A, Okada H. Expression of mir-17-92 enhances anti-tumor activity of t-cells transduced with the anti-egfrviii chimeric antigen receptor in mice bearing human gbm xenografts. J Immunother Cancer. 2013;1:21.

\section{Ready to submit your research? Choose BMC and benefit from:}

- fast, convenient online submission

- thorough peer review by experienced researchers in your field

- rapid publication on acceptance

- support for research data, including large and complex data types

- gold Open Access which fosters wider collaboration and increased citations

- maximum visibility for your research: over $100 \mathrm{M}$ website views per year

At BMC, research is always in progress.

Learn more biomedcentral.com/submissions 